\title{
Neuroleptic malignant syndrome in a young adult female at the university of Benin Teaching Hospital: a case report
}

\author{
Peter I Agbonrofo ${ }^{1}$, John E Osakue ${ }^{2}$
}

1. Department of Surgery,University of Benin Teaching Hospital, PMB 1111, Benin City, Nigeria. Email: pagbonrofo@gmail.com; peter.agbonrofo@uniben.edu. Tel:+234 802-829-6343

2. Department of Anaesthesiology, University of Benin Teaching Hospital, PMB 1111, Benin City, Nigeria. Email: osakuejohn@yahoo.com. Tel:+234 806-036-2070,+234 809-111-4193

\begin{abstract}
Background: Neuroleptic malignant syndrome is a rare but life-threatening idiosyncratic complication following the use of antipsychotic agents, anaesthesia and surgery. It is characterized by hyperthermia, muscle rigidity, autonomic disturbances and mental state alterations.

Case: A 31 year old female weighing $60 \mathrm{~kg}$ received a depot preparation of Fluphenazine on account of depression with psychotic features observed two days prior to elective Cholecystectomy under general anaesthesia. Surgery and anaesthesia were essentially uneventful. Forty eight hours post-operatively, the patient developed features suggestive of neuroleptic malignant syndrome complicated by aspiration pneumonitis. This necessitated her admission into the intensive care unit. She had prolonged stay in the intensive care unit, where she was mechanically ventilated, developed deep venous thrombosis of the left upper limb and required tracheostomy on account of prolonged endotracheal intubation. Patient recovered fully following bromocriptine and dantrolene therapy. She was discharged home after 60 days on admission and has remained in good health.

Conclusion: Though rare, neuroleptic malignant syndrome can occur in young adult females following use of antipsychotics, anaesthesia and surgery. Its clinical course can be prolonged and distressing with the use of depot preparations. Early diagnosis and prompt supportive measures are essential to reduce morbidity and mortality.

Keywords: Neuroleptic malignant syndrome, adult female, University of Benin Teaching Hospital.

DOI: https://dx.doi.org/10.4314/ahs.v18i3.37

Cite as: Agbonrofo PI, Osakue JE. Neuroleptic malignant syndrome in a young adult female at the university of Benin Teaching Hospital: a case report. Afri Health Sci. 2018;18(3): 786-789. https:/ / dx.doi.org/10.4314/abs.v18i3.37
\end{abstract}

\section{Introduction}

Neuroleptic malignant syndrome (NMS) is a rare but life-threatening idiosyncratic complication of antipsychotic treatment characterized by hyperthermia (fever),

\section{Corresponding author:}

Peter I. Agbonrofo,

Department of Surgery,

University of Benin Teaching Hospital,

PMB 1111, Benin City, Edo State, Nigeria.

Phone number +234 802-829-6343

E-mail:pagbonrofo@gmail.com,

peter.agbonrofo@uniben.edu. muscle rigidity, autonomic disturbances and mental state alterations. First described in $1968^{1,2}$, shortly after the introduction of neuroleptics, it occurs in about $0.2 \%$ of patients ${ }^{3}$ treated with the medications (varies from $0.02 \%$ to $\left.2.44 \% 0^{4}\right)$.

Although NMS frequently develops over a 24-72 hour period, the risk of developing NMS may last 10-20 days after discontinuation of neuroleptics or even longer when associated with depot formulations ${ }^{5}$.

There is no single diagnostic tool/test that's been advocated for the diagnosis of NMS hence it's often a diagnosis of exclusion. Levenson ${ }^{1}$ proposed a set of major and minor criteria that indicate a high probability of NMS. The major category includes: fever, rigidity and elevated

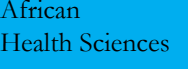

(C) 2018 Agbonrofo et al. Licensee African Health Sciences. This is an Open Access article distributed under the terms of the Creative commons Attribution License (https://creativecommons.org/licenses/BY/4.0), which permits unrestricted use, distribution, and reproduction in any medium, provided the original work is properly cited. 
creatine phosphokinase concentration. The minor category includes: tachycardia, abnormal arterial pressure, tachypnoea, altered consciousness, diaphoresis and leucocytosis. The presence of all three major signs, or two major and four minor signs indicate a high likelihood of the presence of NMS.

NMS commonly affects young adult males and has been reported in both psychiatric and medical/surgical patients or following preoperative use of neuroleptic agents. It occurs more commonly with the typical antipsychotics such as haloperidol and, to a lesser extent, following administration of the newer atypical antipsychotics such as depot fluphenazine ${ }^{4,6,7,8}$. NMS following exposure to anaesthesia and surgery has been reported in some cases ${ }^{9,10,11,12}$.

The clinical management of NMS is largely supportive ${ }^{13}$, following identification and withdrawal of the neuroleptic. Most patients recover completely without residual neurological deficits with intensive care, prompt supportive measures and use of drugs such as bromocriptine, amantadine and dantrolene ${ }^{14}$.

This report is a case of neuroleptic malignant syndrome in a young adult female following depot fluphenazine administration, anaesthesia and surgery in University of Benin Teaching Hospital, Benin City, Nigeria.

\section{Case description}

A 31 year old female, weighing $60 \mathrm{~kg}$, with no history of psychiatric disorder, co-morbid conditions, previous surgical or anaesthetic exposure, was scheduled for elective cholecystectomy on account of resolved calculus cholecystitis. Two days prior to surgery, she was reviewed by the Psychiatrists on account of poor sleep, depressed affect, selective mutism, restlessness, refusal of food/medications and inappropriate speech. A diagnosis of adjustment disorder with depressive features was made and she was commenced on intramuscular (I.M.) Fluphenazine $25 \mathrm{mg}$ stat, oral Benzhexol $5 \mathrm{mg}$ pro re nata (PRN) and oral Amitriptylline 50mg nocte. Over the next two days, her depressive symptoms improved but she remained mute.

Investigation results available, including full blood count, electrolytes and creatinine, were all within normal reference range. She had cholecystectomy with common bile duct exploration under general anaesthesia. Anaesthesia was induced with intravenous (I.V.) propofol 150mg and tracheal intubation with a size $7.5 \mathrm{~mm}$ internal diameter, cuffed endotracheal tube facilitated with I.V. suxamethonium $100 \mathrm{mg}$. Anaesthesia was maintained with isoflurane in oxygen-air mixture while muscle paralysis was maintained with I.V. atracurium. Analgesia was achieved with iv Paracetamol 600mg, iv Ketorolac 30mg and iv tramadol $60 \mathrm{mg}$ while surgical site was infiltrated with $20 \mathrm{mls}$ of $0.125 \%$ Bupivacaine at the end of surgery. Surgery, anaesthesia and the immediate post-op period were essentially uneventful but patient was observed to be mute. Two days post-op, patient was observed to be dyspnoeic, tachypnoeic, with widespread crepitations on chest auscultation, having generalised tremors and muscle rigidity, diaphoresis and persistently febrile. Full blood count done revealed an elevated white blood cell count (16.2 x 103/ $\mu \mathrm{l})$ with relative lymphopenia $(11.9 \%)$ and granulocytosis (81.6\%). Her platelet count was also elevated (536 x 103/ $\mu \mathrm{l})$. A diagnosis of Neuroleptic malignant syndrome with aspiration pneumonitis was made. All neuroleptics were discontinued and she was admitted into the intensive care unit (ICU). Following diagnosis, she was immediately commenced on bromocriptine tablets $2.5 \mathrm{mg} 8$ hourly (via nasogastric tube) while efforts were made to procure parenteral Dantrolene. Active cooling with ice packs and refrigerated intravenous fluids was commenced. A repeat full blood count done on admission into the ICU showed a white blood cell count of $23.7 \times 103 / \mu l$.

A day after admission into the ICU, her trachea was intubated and she was mechanically ventilated with Synchronized Intermittent Mandatory Ventilation mode, using the low tidal volume - high positive end-expiratory pressure approach. Shortly after intubation, she was noticed to be hypotensive despite fluid therapy and was thus commenced on ionotropic support using I.V. noradrenaline at $0.5 \mu \mathrm{g} / \mathrm{kg} / \mathrm{min}$ with good response/effect. Antibiotic therapy as well as Deep Vein Thrombosis (DV'T) prophylaxis were instituted and management (pharmacological and adjuvant) for NMS continued.

Twenty four hours after ICU admission and endotracheal intubation; forty eight hours after ICU admission, she was commenced on Dantrolene capsules $100 \mathrm{mg} 8$ hourly (I.V. preparation could not be sourced) administered via the nasogastric tube. Over the next few days, with resolution of the pneumonitis, she was weaned off the ventilator and also weaned off ionotropic support. However, she could not be extubated (following discontinuation of 
mechanical ventilation on the 6th day after intubation) because her airway reflexes were still depressed and she continued to drool saliva. Oxygen supplementation was continued via a T-piece.

After 72 hours of Dantrolene therapy, hyper-reflexia, muscle hyperkinesia and tremors had reduced significantly and the drug was gradually tailed off. However, a day after discontinuation of the Dantrolene, the tremors were exarcebated and thus, she was recommenced on the medication. She was extubated on the 15th day on ICU admission but had another episode of aspiration two days later necessitating re-intubation and mechanical ventilation. She had bedside elective tracheostomy 5 days later on account of prolonged endotracheal intubation. She was commenced on I.V. Albumin on account of hypo-albuminaemia.

On the 26th day of ICU admission, she developed deep venous thrombosis of the left upper limb despite having been on low molecular weight heparin and regular physiotherapy. The limb was elevated and physiotherapy to that limb discontinued while dosage of anticoagulant (sub-cutaneous clexane) was increased to 40mg 12 hourly and warfarin tablets $2.5 \mathrm{mg}$ nocte and had serial monitoring of clotting profile.

With improvement in symptoms, the dosage of Dantrolene was gradually tailed off and then discontinued. As the DVT resolved and with serial international normalized ratio measurements, anticoagulation was gradually reduced while appropriate physiotherapy continued.

On the 35th day of ICU admission, she was noticed to be progressively withdrawn and uncooperative. She was reviewed bythe psychiatrists and was commenced on Sertraline tablets $50 \mathrm{mg}$ daily. Three days later (43rd day postop, 38th day post ICU admission), she was discharged from the ICU and transferred to the oto-rhino-laryngology ward for continued tracheostomy care (18th day post-tracheostomy).

She was successfully decannulated on the 31 st day post-tracheostomy without adverse sequelae. She continued to make sustained clinical improvement and was discharged home after 60days on admission. Patient continues to be in good health and is being followed up in the clinic on out-patient basis.

\section{Discussion}

As with most rare idiosyncratic complications of therapeutic interventions, diagnosis of NMS may be delayed or missed altogether due to non-specific symptoms and the patient's pre-morbid or co-existing medical conditions ${ }^{12}$. In this case, diagnosis was made early after deterioration of the patient's clinical condition post-operatively.

While the use of a depot preparation of antipsychotic medication prior to surgery may seem reasonable considering the expectation of prolonged fasting or non-suitability of the enteral route, its use in patients without a previously documented history of prior treatment with such medications may be called to question given the risk of prolonged clinical course in the event of the occurrence of severe reactions ${ }^{15}$, as encountered in this case.

Institution of prompt supportive care, especially in an intensive care unit, has been shown to improve the outcome in cases of $\mathrm{NMS}^{13,14}$. This patient may not have survived without such care/management. Airway compromise and aspiration proved to be particularly important challenges in this case and provision of a definitive airway (endotracheal intubation and subsequently, tracheostomy) no doubt proved quite beneficial in this case.

Although parenteral preparations of dantrolene have been the most frequently documented option ${ }^{16}$, this case clearly shows that where such preparations are not available, the oral formulations administered via a nasogastric tube may be equally beneficial and efficacious. After a prolonged and unsuccessful search for the intravenous preparation, we resorted to the use of the oral preparation and achieved quite satisfactory result.

Re-institution of antipsychotic or antidepressant medications may be particularly challenging aspects of care of patients with NMS, especially during the recovery phase $\mathrm{e}^{5}$. Reluctance to recommence any antipsychotics is an understandable reaction following the occurrence of NMS but needless delays in commencing suitably selected medications, especially when clearly indicated, may prolong the recovery and clinical course of such patients. Where such indication exists, the patients and relatives need to be counselled on the need for commencing such medications and available options. Heightened vigilance must 
be maintained to ensure detection of the earliestsigns of relapse, in which case, the medications should be promptly discontinued ${ }^{17}$.

The care of patients with NMS may be complicated by other conditions such as deep venous thrombosis due to prolonged immobilization ${ }^{18}$. Prompt intervention and management of the deep venous thrombosis in this case was instrumental in ensuring a good outcome.

\section{Conclusion}

Though rare, neuroleptic malignant syndrome can occur in young adult females following use of atypical antipsychotics, anaesthesia and surgery. Its clinical course can be prolonged and distressing with the use of depot preparations. Early diagnosis and prompt supportive measures are essential to reduce morbidity and mortality.

\section{Acknowledgements}

The authors acknowledge the efforts of Prof. (Mrs) N.P. Edomwonyi, Dr. S.U. Okugbo, staff of Anaesthesiology and Surgery departments in the preparation of this manuscript and management of this patient.

\section{Conflict of interest disclosure}

The authors declare that there is no conflict of interest.

\section{References}

1. Levenson JL. Neuroleptic malignant syndrome. Am J Psychiatry. 1985;142(10):1137-45.

2. Caroff SN. The neuroleptic malignant syndrome. J Clin Psychiatry. 1980;41(3):79-83.

3. Caroff SN, Mann SC. Neuroleptic malignant syndrome. Med Clin North Am. 1993;77(1):185-202.

4. Ananth J, Parameswaran S, Gunatilake S, Burgoyne K, Sidhom T. Neuroleptic malignant syndrome and atypical antipsychotic drugs. J Clin Psychiatry. 2004;65(4):464 70 .

5. Adnet P, Lestavel P, Krivosic-Horber R. Neuroleptic malignant syndrome. Br J Anaesth. 2000;85(1):129-35. 6. Patra BN, Khandelwal SK, Sood M. Olanzapine induced neuroleptic malignant syndrome. Indian J Pharmacol. 2013;45(1):98 PubMed -9.

7. Hasan S, Buckley P. Novel antipsychotics and the neuroleptic malignant syndrome: a review and critique. Am J Psychiatry. 1998;155(8):1113 PubMed -6.

8. Gleason PP, Conigliaro RL. Neuroleptic malignant syndrome with risperidone. Pharmacotherapy. 1997;17(3):617 PubMed -21.

9. Shaw A, Matthews EE. Postoperative neuroleptic malignant syndrome. Anaesthesia. 1995;50(3):246-7.

10. Patel P, Bristow G. Postoperative neuroleptic malignant syndrome. A case report. Can J Anaesth [Internet]. 1987;34(5):515-8. Available from: http://download.springer.com/static/pdf/920/ art\%253 A $10.1007 \% 252 \mathrm{FBF} 03014361$.pdf? auth66=1393888005_ccec60a4b82d22519f32fc8d$582 \mathrm{~d} 3817 \&$ ext $=. p d f$

11. Young CC, Kaufman BS. Neuroleptic malignant syndrome postoperative onset due to levodopa withdrawal. J Clin Anesth. 1995;7(8):652 PubMed -6.

12. Bhan S, Kulkarni V, Mehta Y, Sharma KK, Trehan N, Suri ML. Neuroleptic malignant syndrome: uncommon postoperative diagnostic dilemma. Asian Cardiovasc Thorac Ann. 2002;10(4):365-6.

13. Susman VL. Clinical management of neuroleptic malignant syndrome. Psychiatr Q. 2001;72(4):325-36.

14. Oruch R, Pryme IF, Engelsen BA, Lund A. Neuroleptic malignant syndrome: An easilyoverlooked neurologic emergency. Vol. 13, Neuropsychiatric Disease and Treatment. 2017. p. 161-75.

15. Gerlach J. Depot neuroleptics in relapse prevention: Advantages and disadvantages. Int Clin Psychopharmacol. 1995;9(Suppl 5):17-20.

16. Ward A, Chaffman MO, Sorkin EM. Dantrolene. A review of its pharmacodynamic and pharmacokinetic properties and therapeutic use in malignant hyperthermia, the neuroleptic malignant syndrome and an update of its use in muscle spasticity. Drugs. 1986;32(2):130-68. 17. Belvederi Murri M, Guaglianone A, Bugliani M, Calcagno P, Respino M, Serafini G, et al. Second-generation antipsychotics and neuroleptic malignant syndrome: systematic review and case report analysis. Drugs R D. 2015;15(1):45 PubMed -62.

18. Chandran GJ, Mikler JR, Keegan DL. Neuroleptic malignant syndrome: case report and discussion. CMAJ. 2003;169(5):439 PubMed -42. 